\title{
WHY ARE LOCALS HAPPIER THAN INTERNAL MIGRANTS? The role of daily life
}

\author{
Martijn Hendriks, Kai Ludwigs, Ruut Veenhoven \\ Social Indicators Research, 125 (2) 481-508 , DOI 10.1007/s11205-014-0856-7
}

\begin{abstract}
Several survey studies have found that internal migrants report lower levels of happiness than locals, even after accounting for socio-economic factors. Traditional global self-ratings reveal that the migrant-local happiness-gap is also present in the data we present. The reasons for the migrant-local happiness-gap are as yet unclear. This paper aims to open this 'black box' by exploring the role of daily activities among a population that has generally been overlooked despite their high migration frequency: young adults. An innovative smartphone application is used that combines two techniques for multiple moment assessment: the Experience Sampling Method and the Day Reconstruction Method. Based on the application data, we examine whether internal migrants spend their time differently than locals and in which situations they feel noticeably less happy than locals. The data reveal that internal migrants distribute less time to happiness-producing activities such as active leisure, social drinking/parties, and activities outside home/work/transit. Internal migrants feel less happy than locals when spending time with friends and while eating. Possible explanations focusing on the role of social capital are discussed. Further analyses reveal that daily life experiences greatly enhance the explanation of the migrant-local happiness-gap. This paper demonstrates the potential value of real-time data and phone applications in solving happiness puzzles.
\end{abstract}

Keywords: internal migration, residential mobility, happiness, subjective well-being, Experience Sampling Method, Day Reconstruction Method

Correspondence: Prof. Dr. Ruut Veenhoven Erasmus University Rotterdam, Faculty of Social Sciences, P.O.B. 17383000 DR Rotterdam, Netherlands and North-West University in South Africa www2.eur.nl/fsw/research/veenhoven 


\section{INTRODUCTION}

Research from multiple countries has found that internal migrants are unable to reach similar levels of happiness as locals (Aksel et al. 2007; Cheng, Wang, and Smyth 2014). Some studies even find migrants to be less happy than people in the place of settlement (locals) and people in the place of origin (stayers), which holds even after controlling for a range of socioeconomic factors (Appleton and Song 2008; Knight and Gunatilaka 2010). A specific, wellresearched case of internal migration is that of German internal migrants after reunification. ${ }^{1}$ Those who moved post-reunification from the former East Germany to the former West Germany have become happier after migration but have not reached similar happiness as former West-Germans over time, whereas West-to-East migrants have become unhappier but remain having higher happiness than East-Germans over time when accounting for sociodemographic factors (Frijters, Haisken-DeNew, and Shields 2004; Fuchs-Schündeln and Schündeln 2009; Melzer 2011). These findings raise three questions: why does the migrantlocal happiness-gap occur? Does the lower general happiness reported by migrants in surveys also translate in less happiness in daily life? What can be done to reduce the gap?

This paper makes a two-fold contribution. The first contribution is theoretical: the current paper progresses current knowledge on internal migrants by opening the 'black box' on factors causing the migrant-local happiness-gap. This is achieved by evaluating the migrantlocal happiness-gap from a new perspective: the role of daily life, which allows us to address the three questions that were raised in the first paragraph. The second contribution is methodological: a pioneering smartphone application is introduced that cost-effectively incorporates two leading research methods to zoom in on daily life: the Experience Sampling Method (ESM) and the Day Reconstruction Method (DRM). Although the application as developed is focused on happiness, the concept of the application is applicable and valuable across many research fields.

This paper specifically focuses on internal migrants to intensify inquiry among scholars and policy makers into this population. Internal migration has remained an underdeveloped theme, especially when compared to international migration. Yet, migrating within a country greatly exceeds the number of international migrants and is a crucial life event, as it largely disrupts and destabilises the pattern of daily life (Molloy, Smith, and Wozniak 2011). Additionally, this paper focuses on a population that has been overlooked in the literature on the happiness of internal migrants: young adults. Ironically, young adults are those who migrate most frequently as they face major life changes such as starting a job, study, family, or moving in with a partner. They are also especially sensitive to life-disruptions because compared to their older peers, they have less self-esteem and life experience, and they are more dependent, less emotionally stable, and more vulnerable to peer pressure (Rosenberg 1965). Hence, this population in particular needs support in making the most of migrating.

What can multiple moment assessments add to general surveys? Global self-reports, based on aggregated data retrieved from memory, are not always exhaustive in explaining sociological, economic, or psychological puzzles (Csikszentmihalyi and Hunter 2003; Kahneman et al. 2004). Hektner, Schmidt, and Csikszentmihalyi suggest that zooming in on people's daily lives can open black boxes that remain closed when using general surveys. Zooming in on daily life provides insight into what one does and how one feels throughout the day. Examples of studies benefiting from such data are Knabe et al. (2010), who use it to 
understand the happiness gap between the employed and the unemployed, and Kahneman et al. (2006), who use it to clarify the weak relationship between income and happiness. Current migration literature has merely used ratings of overall happiness derived from general questionnaires. There is reason to believe that examining daily life in greater detail contributes to explaining the migrant-local happiness-gap. Upon moving, migrants need to build a new social network, create new life patterns, and engage in new activities, organisations, and teams. This substantially impacts daily life in two fashions. First, it can result in a different distribution of time as one's daily routine is disrupted and certain activities are voluntarily or involuntarily initiated or discontinued (e.g., one's job, volunteering, sports). Second, it can lead to less enjoyment of particular daily life activities; for instance, going out with a person one has recently met may be less enjoyable than going out with a long-time friend.

Why incorporate both the ESM and the DRM? Both methods capture a representative sample of individuals' actions, thoughts and feelings throughout the day, across contexts, close to their actual occurrence. In the ESM, respondents are asked to report their present feelings and actions at short notice after receiving each of several signals distributed throughout the day. The DRM asks respondents to complete diaries of the previous day in which the feelings experienced during each performed activity are reported. The unique methodologies imply unique strengths and weaknesses, making co-existence desirable (an extensive discussion is presented in section three). Despite the value of combining these methods, researchers typically choose between these two methods to reduce costs and to increase people's willingness to participate (Diener and Tay 2013). Therefore, a pioneering smartphone application is introduced that cost-effectively combines these methods.

Young adults in the Düsseldorf area (Germany) used the application for two weeks. The multiple moment assessments obtained four sources of information for every period of the day:

1. How the person is feeling

2. What the person is doing

3. Where the person is

4. Who is with the person

The multiple moment assessments began after completing a baseline questionnaire. The baseline questionnaire includes six global measures of subjective well-being, of which four specifically measure global happiness. For all six measures, migrants report lower happiness/subjective well-being than locals. Moving to the data obtained from DRM and ESM, two steps are taken to detect whether migrants and locals also have dissimilar daily life experiences. First, we examine whether migrants distribute less time to happiness-promoting activities, places, and people. Second, we examine whether migrants feel unhappier in certain places, during certain activities, and with certain people. In a subsequent analysis, daily life experiences are moved to the position of explanatory factors to discover the degree to which daily life experiences explain the migrant-local happiness gap present in global self-ratings. Data on da ily life experiences obtained by the smartphone application are shown to have substantial explanatory power, indicating that the two sought-for research contributions are achieved.

The remainder of the paper is organised as follows. Section 2 reviews the literature that relates internal migration to happiness. Section 3 discusses the value and co-existence of the DRM and the ESM. Section 4 introduces the smartphone application used in this paper. Section 5 describes the experimental set-up, and Section 6 presents the results. The final section concludes, discusses, and provides policy implications. 


\section{INTERNAL MIGRATION AND HAPPINESS}

Internal migration is usually defined as the geographical relocation of people over a substantial distance within national borders. The impact of migration on people's lives goes beyond mere 'geographically relocation'. One must adapt to another physical, social, and cultural environment, develop new life patterns, and build new social contacts. It leads to challenges such as finding new friends, communities, hobbies, and sports (teams), implying that stress typically accompanies migration. It offers migrants great opportunities but also substantial risks. The migration literature shows that migrants may not get the best out of migration. Studies in Australia and Turkey have found that 30-50 percent of migrants regret their decision to migrate, implying that it is difficult to overcome the hardships that come with migration (Stimson and Minnery 1998; Aksel et al. 2007; Fozdar and Torezani 2008). Although our study does not focus on pr e-migration versus post-migration happiness development, it is relevant to review studies testing whether migrants gained in happiness by migrating. Recent studies in Finland (Ek et al. 2008), Australia (Kettlewell 2010), and the UK (Nowok et al. 2013) conclude that most people fail to obtain greater happiness by internal migration. These findings imply that migrants do not commonly reach similar levels of happiness as locals, as they do not gain in happiness at all. The gap is shown to be especially relevant for recent migrants, although it is still present among long-term migrants (Knight and Gunatilaka 2010; Cheng et al. 2014).

The key question is why migrants cannot get the best out of migration and how this failure translates into lower levels of happiness in daily life. The social capital literature shows that most migrants face difficulty connecting to others, which makes building new networks an underestimated challenge (Portes 2000; Putnam 2000). Hardships arise because: (1) migrants have little initial social capital via which potential friends can be met; (2) an internal migrant often becomes a member of the out-group because they are seen as 'different', for instance, due to a different accent; and (3) migrants face impaired self-esteem as they are still adapting to the new environment and feel 'pressured' to build new social capital. In daily life, these hardships can translate into feelings of inferiority when being around others, mostly because of being less in one's 'comfort zone', having friendships of lower quality, and lacking social support), and/or spending less time with good friends (e.g., one is less invited to social events). The broaden-and-build theory (Fredrickson 2001) suggests that migrants will spend less time on physically and mentally effortful activities. Namely, internal migrants typically give in on mental health due to the stress that comes with migration (Chen 2011); experiencing negative feelings impairs openness to experiences and reduces activeness because one has less mental energy to distribute. Lower mental health results in less time allocated to effortful events as active leisure, meeting people, and out-ofhome activities. Moreover, migrants may not have access to their preferred activities in the place of settlement, forcing them to discontinue certain activities. Relatedly, migrants may lack the motivation to rebuild in the new place what they had built up in the old place over the years (e.g., one's reputation on a sports team).

Taken together, it suggests that migrants are less engaged in effortful leisure activities. This can reduce happiness, as activity theory suggests that active, social, and challenging activities typically result in higher happiness (Rodríguez, Látková, and Sun 2008). As a byproduct of less social capital, migrants may enjoy social or effortful leisure activities less as they cannot always perform these activities with their long-time friends but have to settle with less close friends. Relatedly, they occasionally need to resort to less desired activities as they have no friends, team, or community with whom they can perform the desired activity (Putnam 2000). The time composition of everyday activities as eating, sleeping, and 
housekeeping is less of a choice, which implies that time distributed to these activities is not so much affected by migrating. Activities where no social and energy-restrictions are involved are also hypothesised to be less affected; examples include in-home activities and individual activities such as reading. In conclusion, it is hypothesised that lower happiness of migrants is particularly caused by less enjoyment of and time composition for social and effortful activities, but to a lesser degree by individual and daily activities.

\section{THE VALUE AND CO-EXISTENCE OF MULTIPLE-MOMENT ASSESSMENTS}

Global self-reports used in prior literature have only allowed the examination of the happiness-gap from a' helicopter-view', whereas tracking daily experiences provides the opportunity for a more detailed look at the migrant-local happiness-gap. The advantages are more diverse. Primarily, global self-reports (e.g., satisfaction with life-as-a-whole) rely on distorted information derived from memory. People face hardships in retrieving all the relevant data from their memory and to subsequently aggregate these data because one's answer depends strongly on recent and vivid experiences (Diener, Inglehart, and Tay 2013). The use of memory and the need for aggregation are minimised for assessments on a momentary (ESM) or daily (DRM) basis; it makes these methods less vulnerable to recalland aggregation bias, implying a better representation of actual experience. ${ }^{2}$ Second, episodic assessments complement global self-reports because the latter typically encloses a strong cognitive component of happiness, whereas the former encloses more 'pure' affective evaluations. An advantage of the ESM is that it promotes ecological validity, as participants provide self-reports in the environment where they truly experience the feelings. A final contribution over traditional cross-sectional studies is that the panel element allows for more robust individual assessments of happiness as biases such as the mood bias are cancelled out on the individual level. The principal limitation of the ESM and DRM are their high costs. A second limitation is that assessments of momentary happiness (i.e., mood) are aggregated to an assessment of long-term happiness, whereas in actuality, the predictors are not exactly the same. A third limitation is that overall scores are biased as participants selectively present information, e.g., participants are reluctant to report that they have been making love (Diener and Tay 2013). Accordingly, global self-reports and episodic assessments are supplementary in assessing happiness.

The key advantages of the DRM over the ESM are: (1) the obtained data cover the complete day, and (2) completing the diaries does not interrupt the flow of daily life, making the DRM less burdensome than the ESM (Diener and Tay 2013). The key advantages of the ESM over the DRM are: (1) superior ecological validity, as participants provide self-reports in the environment and at the moment of truly experiencing the feelings, and (2) it does not face the issue of the DRM that some participants divide the day into more episodes than others, resulting in potential divergent responses between two groups. Their co-existence also gives the opportunity to test for convergent validity of daily life assessments. This is valuable because the psychometric support for the ESM and especially the DRM is limited at this point in time. In conclusion, clear grounds for a multi-method design are present. 


\section{THE SMARTPHONE APPLICATION}

In studies applying the DRM and ESM, experimenters typically handed participants a PDA that had to be used during the experimental period. The use of smartphones has several benefits. First, smartphones promote further ecological validity as participants complete the assessments on a mobile phone to which they are accustomed and which they do not only use for experimental purposes, resulting in lower awareness of 'being followed'. Second, the burden on participants is lower because they do not have to carry around an extra device. This can raise the rates of response and participation. Third, it reduces costs, as no digital devices need to be provided to participants, which implies that there are no costs for purchasing, repairing, and retrieving the equipment. Finally, applications allow for the establishment of 'fuzzy' samples consisting of people who voluntarily and regularly indicate their feelings. With this information, the impact of shocks can be revealed (e.g., the impact of a natural disaster or one's national team winning a soccer match) and data on momentary assessments can be easily collected cross-nationally ${ }^{3}$. The use of smartphone applications has become a more attractive option as many people now own smartphones. We created a costand time-effective happiness application that allows participants to complete both daily happiness diaries and momentary assessments on their personal mobile phones. This is not the first smartphone application developed to examine episodic happiness. Killingworth and Gilbert (2010) successfully used a happiness application for experience sampling, and MacKerron (2011) developed a happiness app to study the influence of the local environment (e.g., the weather) on episodic happiness. The application we introduce has two main advantages over these applications. First, the Day Reconstruction Method is included on top of the Experience Sampling Method. Second, this application is downloadable for Android users, whereas earlier apps focused on i Phone users. Using Android decreases the selfselection problem because approximately 65 percent of smartphone users have Android, whereas iPhone users represent only 25 percent of smartphone users (Kantar World Panel 2014).

\section{METHOD}

\subsection{Sample and procedure}

In the recruitment procedure, individuals were informed that the study involves a tracking of happiness and time-use and that the study incorporates questions about demographics. Individuals were additionally informed of the confidentiality of answers, the possibility to skip a question in any case, and the possibility to opt out of the study at any moment. Interested individuals were asked to list their e-mail address. In exchange for course credit, 123 young adults (17-30 years old) studying psychology in the Düsseldorf area were recruited for participation. Concurrently, 75 young adults living in the Düsseldorf area were recruited via word-of-mouth communication to increase the heterogeneity of the sample (e.g., to include non-students). ${ }^{4}$ To prevent dropout, a lottery was announced in which those who 
completed at least two-third of the diaries and experience samples could win a 250 euro Amazon.com voucher.

The multi-method study consists of three parts: (1) an online questionnaire (2) momentary assessments, and (3) day reconstructions. A brief questionnaire, including a range of measures of happiness and demographic questions, was purposively designed to obtain a baseline-estimate of a person's happiness. All participants completed the baselinequestionnaire on the same evening and were afterwards informed how to download the application onto their mobile phones. After downloading the application, a tutorial with instructions on how to use the application was provided to raise conscientiousness and boost response accuracy. The episodic assessments began for all participants on November, 7, 2013 (Thursday) and lasted for two weeks until November, 21, 2013 (Thursday). Each day, six signals were distributed throughout daytime covering the entire waking day; two consecutive signals were always more than an hour apart. When signalled, participants were asked to indicate (1) how they were feeling, (2) what they were doing, (3) where they were, and (4) who was with them. The activities they could choose from were equal to those of the HappinessIndicator (Oerlemans, Bakker, and Veenhoven 2014) and in line with categorisations made by Kahneman et al. (2004). Every morning, participants were asked to complete a diary of the previous day in which they answer the same four questions.

Participants are included in the analysis when the signal response rate was over 66 percent in both the Experience Sampling Data (56 out of 84) and the daily diaries (10 out of 15). These minima have been successfully surpassed by 109 locals and 41 migrants, indicating an attrition rate of 24 percent. These 150 participants yielded a total of 11,455 momentary assessments and 1,918 day reconstructions. The participants' response rates in the ESM and DRM are, respectively, 91 percent and 85 percent and there were no noteworthy differences in compliance between migrants and locals. One to two minutes for completing an experience sample is supported in literature as being desirable to make the interruptions brief and less intrusive (Hektner et al. 2007). In our study, this was considerable less with an average of about $30 \mathrm{~seconds}$. The time to complete a diary was typically in the range of five to ten minutes.

\subsection{Variables}

\section{Dependent variables.}

To facilitate robust assessments about happiness and subjective well-being, the OECD published guidelines on measuring subjective well-being (OECD 2013) in which they propose including measures for (1) overall happiness (2) sub-elements of happiness (life satisfaction and hedonic affect) and (3) elements of broader subjective well-being (eudaimonic well-being and domain evaluations). The baseline questionnaire follows the proposed structure by including one overall happiness measure, three measures focusing on sub-elements of happiness, and two measures focusing on br oader subjective well-being, although it should be noted that we are mainly interested in the four measures focusing on happiness. Overall happiness is our primary interest and assessed by the question: 'Taking all things together, how happy would you say you are?'. It is answered on a numerical 10-point scale ranging from extremely unhappy to extremely happy. Life satisfaction embodies the cognitive side of happiness. The life satisfaction measure is 'All things considered, how satisfied are you with your life as a whole nowadays?' ranging from 0 ( extremely dissatisfied) to 10 (extremely satisfied). Additionally, a frequently used multiple-item scale to measure life satisfaction is included: Diener's Satisfaction With Life Scale (SWLS; Diener et al 1985). The original 10-item Affect Balance Scale is included to assess the affective side of happiness (Bradburn 1969). The first measure of broader subjective well-being is 
psychological functioning (also referred to as eudaimonia or flourishing) and is measured by the Flourishing Scale (Diener et al. 2010). This scale incorporates eight items (e.g., I lead a purposeful and meaningful life) and is rated on a seven-point scale ( $1=$ strongly disagree; $7=$ strongly agree). Next, participants evaluated satisfaction with ten life domains (e.g., satisfaction with financial status or satisfaction with health status; for the other items, see OECD 2013) on a 10 -point scale $(0=$ not at all satisfied; $10=$ completely satisfied). As recommended by the OECD, every participant started the baseline questionnaire by rating one's overall happiness and finished with rating domain satisfactions to minimise spill-over effects in the measures we are most interested in.

Prior studies applying the DRM or ESM have either used an affect balance scale (multiitem) or a single question on current happiness to assess affective feelings in daily life. We opted for the latter option, operationalized by the questions 'How do you feel?' in the ESM and 'How did you feel' in the DRM and answered on an 11-item numerical scale ranging from 'unhappy' to 'happy', for three reasons. First, it is less of a burden on participants. Second, the single-item measure is strongly correlated with the multi-item measure, implying that the results are largely robust to the measure used (Knabe et al. 2010). Third, there is an ongoing debate about the validity of aggregating specific emotions. When aggregating, there is no agreement on how specific feelings should be weighed against each other (White and Dolan 2009). For instance, joy may have a stronger effect than relaxation. By rating the 1item question, the respondent himself weights which emotions and thoughts are most important for his overall feelings during an activity. Additionally, positive and negative affect do not lie on a single dimension in the affective system, which makes it hazardous to aggregate them (Cacioppo and Bernston 1994).

\section{Independent variables.}

An important reason behind the scant research on internal migrants is that there is no clear boundary between an internal migrant and a local. Two recent studies have utilised a question asking about the spatial distance (measured in kilometres) one has moved (Kettlewell 2010; Nowok et al. 2013). This measure may not be optimal as the 'perceived' distance of migration may depend on $\mathrm{f}$ actors such as one's transportation resources and cultural differences. Measures of cultural distance and travel-time from the place of origin encompass elements that are related to happiness (cultural differences) and other confounding elements (transportation opportunities often serves as a proxy for income), leading to an inherent bias. Therefore, we preferred to use an objective measure: spatial distance. The exact question we used is: 'What is the approximate distance, from the city or town where you lived in before you moved, to the city or town in which you are currently living?'. The five answer-options were 'More than a 1000 kilometres', '100-1000 kilometres', '25-100 kilometres', <25 kilometres' and 'I always lived here'. Due to the limited sample size and to maintain a parsimonious model, we chose to merge these categories into a single 'migrant'-category and a single 'locals'-category. Nowok and colleagues find that those who moved over more than 100 kilometres (long-distance movers) have lower happiness than those who move smaller distances (25-100 kilometres). Kettlewell defined migrants who moved more than 20 kilometres as migrants. We wished to distinguish between those who truly experience the need to build new social lives from those whose daily lives are less affected. Therefore, we categorised those who migrated over 100 kilometres as migrants and other participants as non-migrants. ${ }^{5}$ 


\section{Control variables.}

To minimise self-selection bias, the following factors that are typically associated with happiness are included as covariates in the empirical analysis: age, gender, having a partner, immigrant status (including $1^{\text {st }}$ and $2^{\text {nd }}$ generation immigrants are classified as immigrants), household income, employment status, and whether one has a chronic condition as a proxy for health. ${ }^{6}$ Additionally, personality is incorporated as measured by the 'TIPI-scale' (Gosling, Rentfrow, and Swann 2003). More specific controls for the purposes of our study are also included. These are household situation (as it is strongly correlated to migration), being a student (as a substantial portion of the participants are students), and being born in East Germany (those born in East Germany are typically unhappier).

\subsection{Analytical strategy}

The ESM-data do not only account for momentary happiness but also yield an assessment of a participant's general happiness level by taking the mean of the separate momentary responses (Kahneman 1999). The same applies to the DRM, although one cannot simply aggregate all happiness-assessments as activities have dissimilar durations. We follow previous studies in applying the duration-weighted method of aggregation (e.g., White and Dolan 2009), having the following formula:

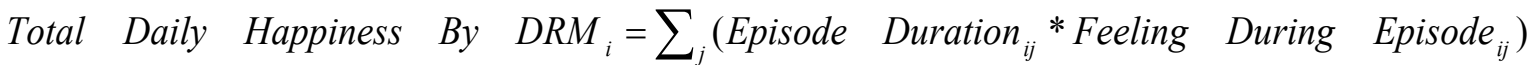

in which $i$ represents an individual and $j$ an episode. This formula is not optimal as it is unlikely that people assign a similar weight to each episode; however, because there is little knowledge concerning the importance of particular episodes in daily life, this method is acknowledged to be best practice. Happiness is commonly treated as being cardinal in subjective well-being literature; we follow this approach as the results of cardinal models are more intuitive and easier to interpret than estimates from ordinal probit models. In addition, cardinal and ordinal analyses of life satisfaction yield, in general, similar results (Ferrer-iCarbonell and Frijters 2004).

The presence of the migrant-local happiness-gap is examined in two steps. First, the presence of differences in happiness between migrants and locals is checked for each of the six global self-reports and for the aggregated scores of the ESM and the DRM. Next, a MANCOVA is applied, which takes the positive correlation between the dependent variables into account. To avoid multicollinearity in the MANCOVA, the rule-of-thumb of Maxwell (2001) is followed, which indicates that dependent variables should be low to moderately correlated with a lower boundary of 0.30 and an upper-boundary of 0.70 . In table 1 , the correlations in bold are very close to or exceed the upper-boundary, which implies that the MANCOVA is likely to suffer from multicollinearity when including all variables. Possible solutions to avoid multicollinearity are (1) the formation of a composite variable, or (2) dropping variables that cause the multicollinearity problem. We opted for the latter option because there is noclear basis for aggregating the measures into an overall measure of subjective well-being, making it hazardous to form a composite variable (OECD 2013). Additionally, the central focus of this paper is the happiness-gap. Therefore, the multivariate effect is based on four elements of happiness that are typically distinguished: overall 
happiness (as measured by the overall happiness measure), daily happiness (by the aggregated score of the day reconstructions), the cognitive element of happiness (by the SWLS), and the affective element of happiness (by the affect balance scale).

To explore the role of daily life, we will proceed by applying two perspectives to zoom in on the data obtained by experience sampling and happiness-diaries. A trait-like perspective is applied to detect possible time-composition effects. The following question is answered from this perspective: do migrants and locals allocate a different amount of time to certain activities, people, and places? Next, a state-like perspective is applied to answer the question: do particular activities, interaction partners, and locations lead to different happiness for migrants and locals? Knabe et al. (2010) refer to differences in happiness for the same type of activity as the 'saddening' effect. To enable more robust, meaningful, and interpretable results, the twenty-one specific activities from which respondents could select when completing their diaries and experience samples (e.g., exercising and eating) are aggregated into five overarching categories derived from the time-and-leisure composition literature (Dardis, Soberon-Ferrer, and Patro 1994). These categories are social leisure/entertainment, active leisure, passive leisure, daily activities, and work-related activities.

Next, we aim to show the incremental value of daily life experiences in explaining the migrant-local happiness-gap. Three OLS-regression models are developed for each of the six global self-ratings, which are the explained variables. Model 1 includes migration as an independent variable and also controls for individual and household characteristics to minimise selection-bias. Model 2 adds the time-composition differences as independent variables to examine the effect of different time-composition on the migrant-local happinessgap. Model 3 presents a full model by including activities in which a clear saddening effect is present as independent variables.

\section{RESULTS}

\subsection{Descriptive statistics}

Migration-specific questions in the baseline-questionnaire reveal that 63 percent of the migrants in the sample moved less than three years ago, half of the migrants moved without knowing any friends or family in the host place, 58 percent plan to live less than three more years in the study area, and 67 percent moved for study purposes. More general sample descriptors are listed in table 2. We will examine two models to analyse the happiness-gap, one including and one excluding the household situation. The reason for this division is that the household situation may have a potential mediating effect on the happiness outcome of migration because a different household situation is a logical consequence of migrating. The correlation matrix (table 2) shows the convergent validity among the data derived from the DRM and the ESM, as the correlation between these methods is significant, sizeable, and larger in magnitude than their correlations with global happiness measures.

\subsection{The migrant-local happiness-gap}

\section{Model A.}

The degree to which the gap is present for each dependent variable when not controlling for household situation, but after controlling for all other covariates included in table 2, is shown in model A of table 3. Univariate results show that locals consistently reported significantly higher scores (at the 10 percent-level) over the six measures. The gaps are somewhat larger for the four global self-ratings of happiness than for eudaimonic well-being and domain satisfactions. The practical importance of the findings is at least as important as the p-values in our study because we combine a limited sample size with a wide range of covariates to minimize selection-bias ${ }^{8}$.The partial eta squares indicate that the effect sizes are modest, which can be considered as 
substantial in the context of happiness. Episodic assessments are typically found to be more rigid (e.g., Knabe et al. 2010), which is also the case in our data. A marginally significant gap is observed for the DRM-data, whereas the ESM-data do not display a statistically significant difference. Using the Bonferroni procedure, the MANCOVA reveals a significant difference between migrants and locals, and a mediocre effect of migration, on the four combined happiness variables $\left(\mathrm{F}(4,130)=2.49 ; \mathrm{p}=.046\right.$; Wilks' Lambda $\left.=.929 ; \eta \rho^{2}=.071\right)$.

\section{Model B.}

The household situation is additionally controlled for in model B of table 3 . The results of model B are highly similar to those of model A. Non-reported results reveal that the low impact of the household situation can be explained by the weak and non-significant relationship between household situation and happiness. The practical and statistical significance of the combined variables is also largely similar to model A $(\mathrm{F}(4,127)=2.31 \mathrm{p}$ $=.061$; Wilks' Lambda $\left.=.932 ; \eta \rho^{2}=.068\right)$. The results suggest that the happiness-gap is not completely driven by differences in demographics and income and that over 6 percent of the multivariate variance of the dependent variables is associated with the migrant-dummy. The episodic assessments in model B do not reveal significant differences between migrants and non-migrants. Nonetheless, substantial happiness-gaps in the aggregated DRM-data and ESM-data remain present, which make it interesting to analyse the DRM-data and ESM-data in more detail to reveal which specific daily experiences cause these gaps. ${ }^{9}$

\subsection{Time-composition of daily activities.}

In this section, a trait-like perspective is applied to zoom in on the time-allocation of migrants and locals. All covariates are included, which provides a substantial degree of certainty that the time-composition differences caused by migrating are filtered. Using the DRM-method, table 4 shows that locals spend significantly more time on active leisure activities. Interestingly, being engaged in active leisure is typically recognised as promoting happiness. When looking at specific activities, it emerges that locals spend significantly more time on social drinking/parties, exercising, and in places other than home/work/transport. In contrast, migrants spend more time on the computer, possibly to communicate with those not living nearby. OLS regressions, controlling for the full set of covariates and the migration-dummy, show that greater time-allocation (in hours) to exercising, social drinking/parties, and places other than home/work/transport, are associated with higher scores on the overall happiness measure in our sample (B's are, respectively, $+.28,+.35$, and +.02). In contrast, spending time on the computer is associated with lower scores on happiness $(B=-.05)$. In sum, we can conclude that time composition seems to play a role in the happiness-gap.

\subsection{Enjoyment of daily activities}

Table 5 applies a state-like perspective to detect whether migrants and locals feel dissimilar happiness during certain episodes. It appears that migrants feel as good as locals during activities such as working and being with colleagues. In contrast, locals report significantly higher happiness scores in both the ESM and the DRM compared to migrants while eating and being with friends. Sizeable gaps are also present in other activities such as intimacy/sex, but no s trong inferences can be drawn as the gaps are not significant due to the limited sample size. The happiness-gap of 'eating' is analysed in greater detail in table $6 .{ }^{10} \mathrm{~A}$ 'deeper' analysis of the eating category reveals that the happiness-gap especially occurs due to locals' greater enjoyment of eating with significant others, which is in line with the fact that migrants generally enjoy being with friends less. Interestingly, we observed in table 4 that locals do not spend more time on eating and with friends. These results suggest that the saddening effect adds unique value in explaining the happiness-gap. On the contrary, time distribution to some other activities is in line with the happiness derived from those activities; that is, locals report both substantially higher happiness and time spent on activities outside home/work/transit and on e xercising. Additionally, migrants spend more time on the computer and appear to enjoy that time more. 


\subsection{The incremental value of daily life experiences}

The final model shows the incremental value of including time composition effects, and saddening effects that consistently and significantly differed between migrants and locals. Table 7 proceeds in stages. In the baseline model (model 1), the full set of covariates is added to minimise the chance that the more extensive models (model 2 and 3) pick up selection effects instead of adding unique explanatory power. In model 2, the time allocation of the five distinguished categories is incorporated and supplemented by the category 'other leisure', as it does not belong in a specific category. Finally, a "full" model is created (model

3 ) in which the consistently-found saddening effects of eating and being with friends are included. The value of model 2 and 3 is threefold.

First, it allows us to examine the degree to which the inclusion of daily life experiences can reduce the coefficient of the migration dummy. Logically, the migration dummy in model 1 is largely similar to the migration gap reported in model B of table 3 as the same covariates are included but a different statistical procedure is applied. When also including time allocation (model 2), the gap decreases for all dependent variables relative to the first model and becomes insignificant for four of the six variables. The gap decreases further when saddening effects are included (model 3), resulting in insignificant migration variables for all dependent variables. Although part of the gap remains present in model 3, the gap decreases substantially in comparison to the less comprehensive models. Hence, daily assessments are valuable contributions in explaining the happiness-gap.

Second, the decreased gap can be explained by examining the effect of the time spending categories and saddening effects on the dependent variables. Active leisure is positively related to happiness and partially explains the gap because locals spend more time on this happiness-producing activity. Feeling good while eating and being with friends is also associated with higher scores for the dependent variables. One's feelings with friends can be expected to have a stronger association with long-term happiness than one's feelings during eating as social networks are crucial for people. Interestingly, the reverse was consistently found over the dependent variables. Note, however, that the gap in eating is largely caused by enjoying eating with friends less.

Finally, we examine whether each progressive model has incremental value in explaining general happiness and subjective well-being. For this purpose, adjusted $\mathrm{R}$ squared statistics are reported because they impose a penalty on additional parameters to a model. Models 2 and 3 have incremental value in explaining each dependent variable as the R-square rises in any case from model 1 to model 2 and from model 2 to model 3 . This implies that time composition and differences in momentary feelings are valuable explanatory factors, on top of individual and household characteristics, for explaining subjective well-being and happiness.

\subsection{Robustness check}

The cross-sectional data cannot rule out the possibility that the migration effect is driven by migrants who are genetically unhappier than locals and therefore never obtain a similar happiness level. For multiple reasons, it is unlikely that the entire migration gap would be caused by genetics; German internal migrants after reunification appeared to be somewhat happier than non-migrants (Fuchs-Schündeln and Schündeln 2009), migrants are typically self-confident and optimistic individuals, which correlates with higher happiness (Knight and Gunatilaka 2010), and the gap we observe remains sizeable after controlling for personality. Still, a more formal test of possible selectivity would increase the leverage of the results. Therefore, we follow Bartram (2013) in applying a 2-stage treatment effects model. ${ }^{11}$ 
The goal of the first stage is to obtain an estimation of the probability that one migrates. For this purpose, an instrumental variable is needed to predict the probability that someone would migrate, in addition to factors that affect the decision to migrate but cannot be affected by the act of migration (age and gender in our study). The instrumental variable must be strongly related to the independent variable (i.e., the migration-decision) but unrelated to the dependent variable (i.e., happiness). Spatial distance in kilometers to the nearest university offering a psychology-programme was chosen as an instrument. That is, most migrants indicated moving for the purpose of studying psychology (67 percent), which implies that only those who lived far away from a university felt the need to migrate (see column 1 in table 8). The distance to a psychology programme is unrelated to happiness. The adoption of this instrument implies that only the student population of our sample was utilised in this analysis $(\mathrm{N}=101)$. The second stage examines the effects of the independent variables on happiness. ${ }^{12}$ A residual for each observation is obtained in both stages. Estimates are biased in a standard OLS if the unobservables in stage 1 are correlated with the unobservables in the stage $2 \mathrm{~m}$ odel. The negative $\rho$ in table 8 indicates a negative correlation between the unobservables in the first stage and in the second stage. Thus, unobservables are negatively (positively) related to migration and positively (negatively) related to happiness. This suggests that, if at all, migrants are positively selected from the population in terms of happiness, implying an increased gap when further removing selection effects. This is confirmed when looking at the coefficient sizes of a standard OLS $(B=.42)$ and the two-stage model $(\mathrm{B}=.51)$. The insignificant $\lambda$ indicates that there is no ground for preferring this more advanced model over a basic OLS-model.

\section{DISCUSSION}

The key goals of this paper have been to present a widely applicable methodology that can accurately zoom in on daily life and to advance the migration literature by addressing why internal migrants are typically unhappier than locals from a new point of view: the role of daily life. Global self-reports reveal that a gap remains present among young adults after controlling for socio-demographic differences. These gaps are shown to be particularly caused by a different experience of daily life. One part of the explanation comes from a different distribution of time. The young adult migrants allocated less time to active leisure and activities outside of home/work/transit. Specifically, they spent significantly less time on exercising and social drinking/parties. This is unfortunate as these activities are all associated with high momentary happiness and high global self-ratings of happiness. A possible explanation for the time composition differences can be drawn from the broaden-and-build theory (Fredrickson 2001). The stressful lives of migrants lead them to have less mental and physical energy to engage in happiness-promoting activities as they are typically effortful. A snowball develops in which less openness to, and energy for, happiness-promoting activities leads to less positive feelings, which subsequently leads again to less mental energy, and so on. Locals also spend more time on the computer, which is generally associated with lower happiness. However, migrants were somewhat happier than locals when spending time on the computer. A profound reason for higher enjoyment and more time allocated to the computer may be the use of social media on the computer as a tool to communicate with their friends and family who do not live close by. Another part of the explanation for the migrant-local happiness-gap comes from lower happiness of migrants while being with friends and while eating. The lower enjoyment of eating is not caused by eating with friends less often, but by experiencing less enjoyment while eating with friends. The social capital literature provides two potential explanations for migrants' lower enjoyment when being or eating with friends. Locals have lived in a certain place for a long time and have therefore had the opportunity to be selective in choosing friends and maintaining relationships over time. Migrants have had limited opportunities to build new social networks and must therefore choose from a considerably smaller pool of people (Putnam 2000). Relatedly, migrants' ties with others are typically not as strong as the ties that locals have with their long-time friends, leading to 
feelings of low social support and lower levels of comfort while spending time with the "new friends' (Portes 2000). Temporal comparison processes may augment the dissatisfaction with the current friends because the less intimate new friends are negatively compared to longtime friends in the place of origin. Both the time composition differences and the differences in momentary happiness while being with friends explain a substantial part of the migrantlocal happiness-gap.

The knowledge regarding the impact of internal migration on ha ppiness is limited, especially compared to international migration. This paper reveals that migrants can benefit from aid in daily life decisions. From a policy perspective, migrants appear to benefit from help in building new social lives and engaging in positive experiences such as active leisure. This can be achieved by local governments offering help, information, or discounts to migrants for becoming engaged in new communities and social- and active leisure activities in the host region. National governments can reduce migration stress by simplifying moving processes, such as the process of registering in a new city.

Methodologically, we show that the use of technologies that zoom in on daily life add to the explanation of global subjective well-being. Future research can solve other economic, sociological, and psychological puzzles by using cost-effective smartphone applications that zoom in on the phenomenon under interest to obtain detailed information that is difficult to derive from general surveys. The black boxes opened by this methodology can greatly benefit public policy making as it helps to clarify what causes particular phenomena, thereby offering a step forward in acting upon these problems and thereby improving happiness in society.

Despite its contributions, this study also has limitations. The independent variable may not have been optimal as spatial distance may be different to perceived distance. The future robustness of findings on internal migration can be improved by the development of an index of perceived distance including factors as travelling time and culture distance and complementing the measure of spatial distance. Another limitation was our sample; it was quantitatively limited, directed to a specific region, and included mostly females. We encourage future studies to check whether our results are generalisable to other regions, countries, and populations. A limitation in the measurement of happiness was that participants completed all six global subjective well-being scales consecutively, which lowers the advantages of measuring multiple constructs as biases as the impact of mood and question-order may consistently occur in the baseline-questionnaire. A limitation of applying both the ESM and the DRM is that there are likely to be carry-over effects from one activity to the next. A final limitation was the cross-sectional research design. Although we managed to minimise the chance of selection biases by using a two-stage model, a longitudinal design incorporating pre-migration data would have been preferable. Yet, longitudinal datasets incorporating migration-data are largely unavailable and therefore this study is not an exception in having to resort to cross-sectional data.

In conclusion, by relating the introduced smartphone application to $a b$ aseline questionnaire, we show the incremental value that multiple moment assessments can bring to general surveys in advancing knowledge. In this paper, this technology has been valuable in explaining the migrant-local happiness-gap by revealing the role of daily life experiences. We hope human knowledge will be advanced by applying similar technology on a wider scale.

\section{Acknowledgments}

The authors thank Stephan Erdtmann for technological help with constructing the application and Martijn Burger and Thomas de Vroome for comments on earlier versions. 


\section{REFERENCES}

Aksel, Ş., Gün, Z., Irmak, T. Y., \& Cengelci, B. (2007).

Migration and psychological status of adolescents in Turkey.

Adolescence, 42, 589-602.

Appleton, S., Song, L. (2008).

Life satisfaction in urban China: Components and determinants.

World Development, 36, 2325-2340.

Bartram, D. (2013).

Happiness and 'Economic Migration': A comparison of Eastern European Migrants and

Stayers.

Migration Studies, 1, 156-75.

Bradburn, N. M. (1969).

The structure of psychological well-being.

Chicago: Aldine.

Cacioppo, J. T., \& Bernston, G.G. (1994).

Relationship between attitudes and evaluative space: A critical review, with emphasis on the separability of positive and negative substrates.

Psychological Bulletin, 115, 401-423.

Chen, J. (2011).

Internal migration and health: Re-examining the healthy migrant phenomenon in China.

Social Science \& Medicine, 72, 1294-1301.

Cheng, Z., Wang, H., \& Smyth, R. (2014).

Happiness and job satisfaction in urban China: A comparative study of two generations of migrants and urban locals.

Urban Studies, 51, 2160-2184.

Cohen, J. (1992).

Quantitative methods in psychology: A power primer.

Psychological Bulletin, 112, 155-159.

Csikszentmihalyi, M., \& Hunter, J. (2003).

Happiness in everyday life: The uses of experience sampling.

Journal of Happiness Studies, 4, 185-199.

Dardis, R., Soberon-Ferrer, H., \& Patro, D. (1994).

Analysis of leisure expenditures in the United States.

Journal of Leisure Research, 26, 309-321.

Diener, E. D., Emmons, R.A., Larsen, R.J., \& Griffin, S. (1985).

The satisfaction with life scale.

Journal of Personality Assessment, 49, 71-75. 
Diener E., Inglehart R., \& Tay L. (2013).

Theory and validity of life satisfaction scales.

Social Indicators Research, 112, 497-527.

Diener, E., \& Tay, L. (2013).

Review of the day reconstruction method (DRM).

Social Indicators Research, 116, 255-267.

Diener, E., Wirtz, D., Tov, W., Kim-Prieto, C., Choi, D.W., Oishi, S., et al. (2010).

New well-being measures: Short scales to assess flourishing and positive and negative feelings.

Social Indicators Research, 97, 143-156.

Ek, E., Koiranen, M., Raatikka, V. P., Järvelin, M.R., \& Taanila, A. (2008)

Psychosocial factors as mediators between migration and subjective well-being among young Finnish adults.

Social Science \& Medicine, 66, 1545-1556.

Ferrer-i-Carbonell, A., \& Frijters, P. (2004).

How important is methodology for the estimates of the determinants of happiness?.

The Economic Journal, 114, 641-659.

Fozdar, F., \& Torezani, S. (2008)

Discrimination and Well-Being: Perceptions of Refugees in Western Australia.

International Migration Review 42: 30-63.

Fredrickson, B. L. (2001).

The role of positive emotions in positive psychology: The broaden-and-build theory of positive emotions.

American Psychologist, 56, 218-226.

Frijters, P., Haisken-DeNew, J. P., \& Shields, M. A. (2004).

Money does matter! Evidence from increasing real income and life satisfaction in East

Germany following reunification.

American Economic Review, 94, 730-740.

Fuchs-Schündeln, N., \& Schündeln, M. (2009).

Who Stays, Who Goes, Who Returns? East-West Migration Within Germany Since

Reunification.

Economics of Transition, 17, 703-738.

Gosling, S. D., Rentfrow, P. J., \& Swann, W. B. (2003).

A Very Brief Measure of the Big Five Personality Domains.

Journal of Research in Personality, 37, 504-528.

Hektner, J. M., Schmidt, J. A., \& Csikszentmihalyi. M. (2007)

Experience sampling method: Measuring the quality of everyday life.

Thousand Oaks, CA: Sage Publications, Inc. 
Kahneman, D. (1999).

Objective happiness.

In: D. Kahneman, E. Diener and N. Schwartz (eds), Well-being: The Foundations of Hedonic Psychology.

New York: Russel Sage. pp. 3-25.

Kahneman, D., Krueger, A. B., Schkade, D. A., Schwarz, N., \& Stone, A. A. (2004).

A survey method for characterizing daily life experience: The day reconstruction method.

Science Magazine, 306, 1776-1780.

Kahneman, D., Krueger, A.B., Schkade, D., Schwarz, N., \& Stone, A. A. (2006).

Would you be happier if you were richer? A focusing illusion.

Science Magazine, 312, 1908-1910.

Kantar World Panel (2014).

Available: http://www.kantarworldpanel.com/Global/News/Android-ends-the-year-on-topbut-Apple-scores-in-key-markets

Kettlewell, N. (2010).

The impact of rural to urban migration on wellbeing in Australia.

The Australasian Journal of Regional Studies, 16, 187-213.

Killingsworth, M. A., \& Gilbert, D. T. (2010).

$A$ wandering mind is an unhappy mind.

Science Magazine, 330, 932.

Knabe, A., Rätzel, S., Schöb, R., \& Weimann, J. (2010).

Dissatisfied with life but having a good day: Time-use and well-being of the unemployed. The Economic Journal, 120, 867-889.

Knight, J., \& Gunatilaka, R. (2010).

Great expectations? The subjective well-being of rural-urban migrants in China.

World Development, 38, 113-124.

MacKerron, G. (2011).

Implementation, implementation, implementation: Old and new options for putting surveys and experiments online.

Journal of Choice Modelling, 4, 20-48.

Maxwell, S. (2001).

When to Use MANOVA and Significant MANOVAs and Insignificant ANOVAs or Vice Versa. Journal of Consumer Psychology, 10, 29-30.

Melzer, S.M. (2011).

Does migration make you happy? The influence of migration on subjective well-being. Journal of Social Research \& Policy, 2, 73-92.

Molloy, R., Smith, C. L., \& Wozniak, A.K. (2011). Internal migration in the United States (No. w17307).

National Bureau of Economic Research. 
Nowok, B., Van Ham, M., Findlay, A.M., \& Gayle, V. (2013).

Does migration make you happy? A longitudinal study of internal migration and subjective well-being.

Environment and Planning A, 45, 986-1002.

Oerlemans, W., Bakker A. B., \& Veenhoven, R. (2014).

Available: http://www.gelukswijzer.nl/happinessindicator/gw/

Organisation for Economic Co-operation and Development (OECD) (2013).

$\mathrm{O} E C D$ guidelines on measuring subjective wellbeing.

Paris: OECD Publishing.

Portes, A. (2000).

Social Capital: Its Origins and Applications in Modern Sociology.

Boston: Butterworth-Heinemann.

Putnam, R. D. (2000).

Bowling alone: the collapse and revival of American community.

New York, NY, USA: Simon and Schuster

Redelmeier, D. A., Katz, J., \& Kahneman, D. (2003)

Memories of colonoscopy: A randomized trial.

Pain, 104, 187-194.

Rodríguez, A., Látková P., \& Sun, Y. Y. (2008).

The relationship between leisure and life satisfaction: Application of activity and need theory.

Social Indicators Research, 86, 163-175.

Rosenberg, M. (1965).

Society and the adolescent self-image.

Princeton, NJ: Princeton University Press.

Stimson R. J., \& Minnery, J. (1998).

Why people move to the 'sun-belt': A case study of long-distance migration to the Gold Coast, Australia.

Urban Studies, 35, 193-214.

White, M. P., \& Dolan, P. (2009).

Accounting for the richness of daily activities.

Psychological Science, 20, 1000-1008. 


\section{NOTES}

${ }^{1}$ This is also recognised as semi-internal migration, as former West Germany (BRD) and former East Germany (DDR) were reunited into one Germany in 1990, but faced significant social, economic, and cultural differences.

2 Some degree of memory bias is likely to be present when applying DRM, for instance, due to the "peak-end-rule" (Redelmeier, Katz, and Kahneman 2003). The bias remains acceptable, however, because people are shown to have adequate access to relevant information for indicating their feelings on the previous day (Kahneman et al. 2004). 3 This advantage is not yet applicable to our application as we lacked the resources to publicly introduce and promote the application.

4 Additionally, 11 young adults not living in the Dusseldorf area and 21 adults over the age of 30 were recruited but not considered for analysis as they introduced potential endogenous biases (e.g., living in a happier or unhappier region or migrated decades ago).

5 Analyses distinguishing the 109 locals in 55 non-movers and 54 short-distance movers ( $<100$ kilometers) reveal no significant differences on all six subjective-well being measures; analyses are available on request.

6 An education variable, asking about the highest level of education completed is excluded because it was highly correlated with age $(\mathrm{r}=0.82)$. The high correlation is plausible given our sample of young adults.

7

Robustness checks are performed by replacing the 1-item life satisfaction measure with the SWLS and replacing the overall day reconstruction score with the overall experience sampling score. The outcomes are in line with the reported results; results are available on request.

8 According to Cohen (1992), effect sizes should be interpreted as follows: $\eta \rho^{2}=0.01$ as small, $\eta \rho^{2}=0.06$ as medium, and $\eta \rho^{2}=0.14$ as large.

9 Further robustness analyses suggest that the happiness-gap between migrants and locals was largely unaffected by (1) excluding a minimum boundary for signal response rate, (2) including people over 30 years old, or (3) including those not living in the Düsseldorf region; results are available on request.

10 A more detailed analysis of 'friends' did not appear to be useful due to the limited sample size per activity.

11 This type of 'Heckman' model applies a probit model in the first stage to reflect on the binary nature of the migration decision.

12 Similar results are found when using other dependent variables; results are available on request. 
Table 1. Correlation-matrix of subjective well-being measures.

\begin{tabular}{|c|c|c|c|c|c|c|c|c|}
\hline \multicolumn{9}{|c|}{ Pearson Correlation coefficient (r) } \\
\hline & ESM & DRM & $\begin{array}{c}\text { Overall } \\
\text { happiness }\end{array}$ & $\begin{array}{l}\text { 1-item life } \\
\text { satisfaction }\end{array}$ & $\begin{array}{c}\text { Affect } \\
\text { Balance }\end{array}$ & SWLS & Eudaimonia & Domains \\
\hline ESM & $\mathrm{x}$ & & & & & & & \\
\hline DRM & 0.80 & $\mathrm{x}$ & & & & & & \\
\hline Overall happiness & 0.45 & 0.34 & $\mathrm{x}$ & & & & & \\
\hline 1-item life satisfaction & 0.42 & 0.34 & 0.64 & $\mathrm{x}$ & & & & \\
\hline Affect Balance & 0.46 & 0.33 & 0.48 & 0.39 & $\mathrm{x}$ & & & \\
\hline SWLS & 0.46 & 0.38 & 0.53 & 0.68 & 0.40 & $\mathrm{x}$ & & \\
\hline Eudaimonia & 0.42 & 0.36 & 0.44 & 0.49 & 0.43 & 0.67 & $\mathrm{x}$ & \\
\hline Domains & 0.45 & 0.41 & 0.53 & 0.61 & 0.44 & 0.74 & 0.69 & $\mathrm{x}$ \\
\hline
\end{tabular}

Note: all correlations are significant at the $1 \%$ level. 
Table 2. Descriptive characteristics of the sample

\begin{tabular}{|c|c|c|c|c|}
\hline Variable & $\begin{array}{c}\text { Full sample } \\
150 \\
\text { Mean }(S D) / \% \\
\end{array}$ & $\begin{array}{c}\text { Migrants } \\
41 \\
\text { Mean }(S D) / \% \\
\end{array}$ & $\begin{array}{c}\text { Locals } \\
109 \\
\text { Mean }(S D) / \% \\
\end{array}$ & F statistic \\
\hline Age in years & $21.7(3.10)$ & $22.7(3.19)$ & $21.4(2.99)$ & $5.99 *$ \\
\hline Gender ( $\%$ male $)$ & $18 \%$ & $10 \%$ & $21 \%$ & \\
\hline Has a partner & $50 \%$ & $54 \%$ & $49 \%$ & \\
\hline (Psychology) Students & $73 \%$ & $71 \%$ & $73 \%$ & \\
\hline \multicolumn{5}{|l|}{ Personality } \\
\hline Extraversion & $4.08(0.66)$ & $4.13(0.52)$ & $4.06(0.71)$ & \\
\hline Conscientiousness & $3.99(0.63)$ & $4.00(0.58)$ & $3.98(0.65)$ & \\
\hline Openness & $4.18(0.78)$ & $4.18(0.73)$ & $4.18(0.80)$ & \\
\hline Agreeableness & $4.52(0.80)$ & $4.62(0.80)$ & $4.48(0.80)$ & \\
\hline Emotional stability & $3.83(0.73)$ & $3.82(0.78)$ & $3.83(0.72)$ & \\
\hline Chronic condition & $21 \%$ & $27 \%$ & $19 \%$ & \\
\hline Immigrant & $14 \%$ & $17 \%$ & $13 \%$ & \\
\hline Born in East-Germany & $4 \%$ & $10 \%$ & $2 \%$ & $4.96 *$ \\
\hline Monthly Income & & & & $6.75 *$ \\
\hline Below modal & $69 \%$ & $88 \%$ & $62 \%$ & \\
\hline Modal (€2.500 net) & $19 \%$ & $7 \%$ & $23 \%$ & \\
\hline Above modal & $11 \%$ & $5 \%$ & $13 \%$ & \\
\hline Having a job (\% yes) & $44 \%$ & $44 \%$ & $44 \%$ & \\
\hline Household situation & & & & $6.75 *$ \\
\hline At parents' home & $41 \%$ & $22 \%$ & $48 \%$ & \\
\hline Alone & $21 \%$ & $29 \%$ & $17 \%$ & \\
\hline With partner & $19 \%$ & $17 \%$ & $20 \%$ & \\
\hline Flat-sharing with others & $19 \%$ & $32 \%$ & $15 \%$ & \\
\hline
\end{tabular}


Table 3. Univariate differences in happiness and subjective well-being.

\begin{tabular}{|c|c|c|c|c|c|c|c|c|}
\hline \multicolumn{2}{|c|}{$\begin{array}{c}\text { Model A - all covariates, except for } \\
\text { household situation }\end{array}$} & \multicolumn{2}{|c|}{$\begin{array}{c}\text { Locals } \\
109\end{array}$} & \multicolumn{2}{|c|}{$\begin{array}{c}\text { Migrants } \\
41\end{array}$} & \multirow{2}{*}{$\begin{array}{l}\text { Mean difference } \\
\text { Locals-Migrants }\end{array}$} & \multirow{2}{*}{$\begin{array}{l}\text { ANCOVA test } \\
(d f=134) \\
F \text {-statistic }\end{array}$} & \multirow{2}{*}{$\begin{array}{c}\text { Effect size } \\
\eta \rho^{2}\end{array}$} \\
\hline & & Adj.Mean & SE & Adj. Mean & SE & & & \\
\hline Overall happiness & $(0-10)$ & 6.56 & 0.15 & 5.96 & 0.25 & 0.60 & $4.09 *$ & .030 \\
\hline 1-item life satisfaction & $(0-10)$ & 6.60 & 0.19 & 5.97 & 0.32 & 0.63 & $2.75^{+}$ & .020 \\
\hline Affect Balance & $(-5 ; 5)$ & +0.91 & 0.16 & +0.02 & 0.28 & 0.89 & $7.22 *$ & .051 \\
\hline 5-item SWLS & $(1-7)$ & 5.05 & 0.09 & 4.64 & 0.16 & 0.41 & $4.74 *$ & .034 \\
\hline Eudaimonic well-being & $(1-7)$ & 5.43 & 0.08 & 5.12 & 0.13 & 0.31 & $3.78^{+}$ & .027 \\
\hline Domain satisfactions & $(0-10)$ & 6.77 & 0.13 & 6.31 & 0.21 & 0.46 & $3.29^{+}$ & .024 \\
\hline Day reconstruction & $(0-10)$ & 6.67 & 0.08 & 6.37 & 0.13 & 0.30 & $3.41^{+}$ & .025 \\
\hline Experience sampling & $(0-10)$ & 6.53 & 0.08 & 6.32 & 0.14 & 0.19 & 1.57 & .012 \\
\hline \multirow{2}{*}{\multicolumn{2}{|c|}{ Model B - All covariates included }} & \multicolumn{2}{|c|}{$\begin{array}{c}\text { Locals } \\
109\end{array}$} & \multicolumn{2}{|c|}{$\begin{array}{c}\text { Migrants } \\
41\end{array}$} & Mean difference & $\begin{array}{l}\text { ANCOVA test } \\
(d f=131)\end{array}$ & Effect size \\
\hline & & Adj.Mean & SE & Adj. Mean & SE & Locals-Migrants & $F$-statistic & $\eta \rho^{2}$ \\
\hline Overall happiness & $(0-10)$ & 6.57 & 0.15 & 5.93 & 0.26 & 0.64 & $4.19 *$ & .031 \\
\hline 1-item life satisfaction & $(0-10)$ & 6.58 & 0.19 & 6.01 & 0.32 & 0.57 & 2.19 & .016 \\
\hline Affect Balance & $(-5 ; 5)$ & +0.91 & 0.17 & +0.02 & 0.29 & 0.93 & $6.82 * *$ & .049 \\
\hline 5-item SWLS & $(1-7)$ & 5.06 & 0.09 & 4.63 & 0.16 & 0.43 & $4.87 *$ & .036 \\
\hline Eudaimonic well-being & $(1-7)$ & 5.43 & 0.08 & 5.12 & 0.14 & 0.31 & $3.49+$ & .026 \\
\hline Domain satisfactions & $(0-10)$ & 6.78 & 0.13 & 6.30 & 0.22 & 0.48 & $3.28+$ & .024 \\
\hline Day reconstruction & $(0-10)$ & 6.66 & 0.08 & 6.40 & 0.14 & 0.26 & 2.42 & .018 \\
\hline Experience sampling & $(0-10)$ & 6.52 & 0.08 & 6.34 & 0.14 & 0.18 & 1.15 & .009 \\
\hline
\end{tabular}

Note: Bonferroni adjustment for multiple dependent variables

Significance levels at the $10 \%, 5 \%$, and $1 \%$ level are denoted by ${ }^{+}, *$, and ** respectively 
Table 4. Happiness from a trait-like perspective (DRM-data)

\begin{tabular}{|c|c|c|c|}
\hline \multicolumn{4}{|c|}{ Time-allocation } \\
\hline & Locals & Migrants & \\
\hline & 109 & 41 & $A N C O V A$ \\
\hline & \multicolumn{2}{|c|}{ Mean time a day (Hours:minutes) } & $F$-statistic \\
\hline Social leisure/entertainment & $1: 22$ & 1:19 & \multirow{6}{*}{$7.66^{* *}$} \\
\hline Social drinks and partying & $0: 19$ & 0:05 & \\
\hline Visiting cinema, theatre, or sports & 0:08 & $0: 11$ & \\
\hline Talking & $0: 34$ & $0: 40$ & \\
\hline Shopping & 0:07 & 0:09 & \\
\hline Institutional event (e.g. church-event) & $0: 14$ & $0: 14$ & \\
\hline Active Leisure & $0: 55$ & $0: 32$ & \multirow[t]{2}{*}{$4.70^{*}$} \\
\hline Intimacy/sex & 0:08 & 0:07 & \\
\hline Exercising & $0: 24$ & $0: 12$ & \multirow[t]{2}{*}{$3.68^{+}$} \\
\hline Hobbies & $0: 23$ & $0: 13$ & \\
\hline Passive Leisure & $2: 50$ & $2: 48$ & \multirow{18}{*}{$4.18 *$} \\
\hline Reading & 0:08 & 0:07 & \\
\hline Watching TV & $1: 28$ & $1: 27$ & \\
\hline Listening to music & 0:05 & 0:08 & \\
\hline On the Computer & $0: 18$ & $0: 39$ & \\
\hline Resting & $0: 51$ & $0: 27$ & \\
\hline Other leisure & $0: 48$ & $0: 38$ & \\
\hline Daily activities & 4:09 & $4: 30$ & \\
\hline Eating & 1:09 & 1.22 & \\
\hline Taking care of others & $0: 12$ & $0: 20$ & \\
\hline Cooking & $0: 13$ & 0:09 & \\
\hline In transit & $1: 40$ & $1: 42$ & \\
\hline Getting up and ready & $0: 55$ & 1:06 & \\
\hline Work-related activities & $5: 57$ & $6: 14$ & \\
\hline Housekeeping & $0: 37$ & $0: 40$ & \\
\hline Working & 1:09 & 1:07 & \\
\hline Studying & $4: 11$ & $4: 27$ & \\
\hline Total & $16: 16$ & 16:09 & \\
\hline \multicolumn{4}{|c|}{ Interaction partners } \\
\hline Partner & $2: 09$ & $1: 51$ & \\
\hline Friends & $3: 43$ & $4: 00$ & \\
\hline Direct family & $1: 40$ & $1: 56$ & \\
\hline Alone & $7: 16$ & $7: 10$ & \\
\hline Colleagues & $1: 21$ & $1: 21$ & \\
\hline Total & 16:09 & $16: 18$ & \\
\hline \multicolumn{4}{|c|}{ Locations } \\
\hline Elsewhere out of house & $6: 20$ & $5: 20$ & $3.35^{+}$ \\
\hline At home & $7: 51$ & $8: 26$ & \\
\hline At work & $1: 05$ & $1: 30$ & \\
\hline In public transport/vehicle & $0: 55$ & 1:03 & \\
\hline Total & $16: 11$ & $16: 19$ & \\
\hline
\end{tabular}

Note: Mean time a day corrected for differences in all covariates listed in table 1. Significance levels at the $10 \%, 5 \%$, and $1 \%$ level are denoted by ${ }^{+}, *$, and $* *$ respectively 
Table 5. Happiness from a state-like perspective in the ESM and the DRM

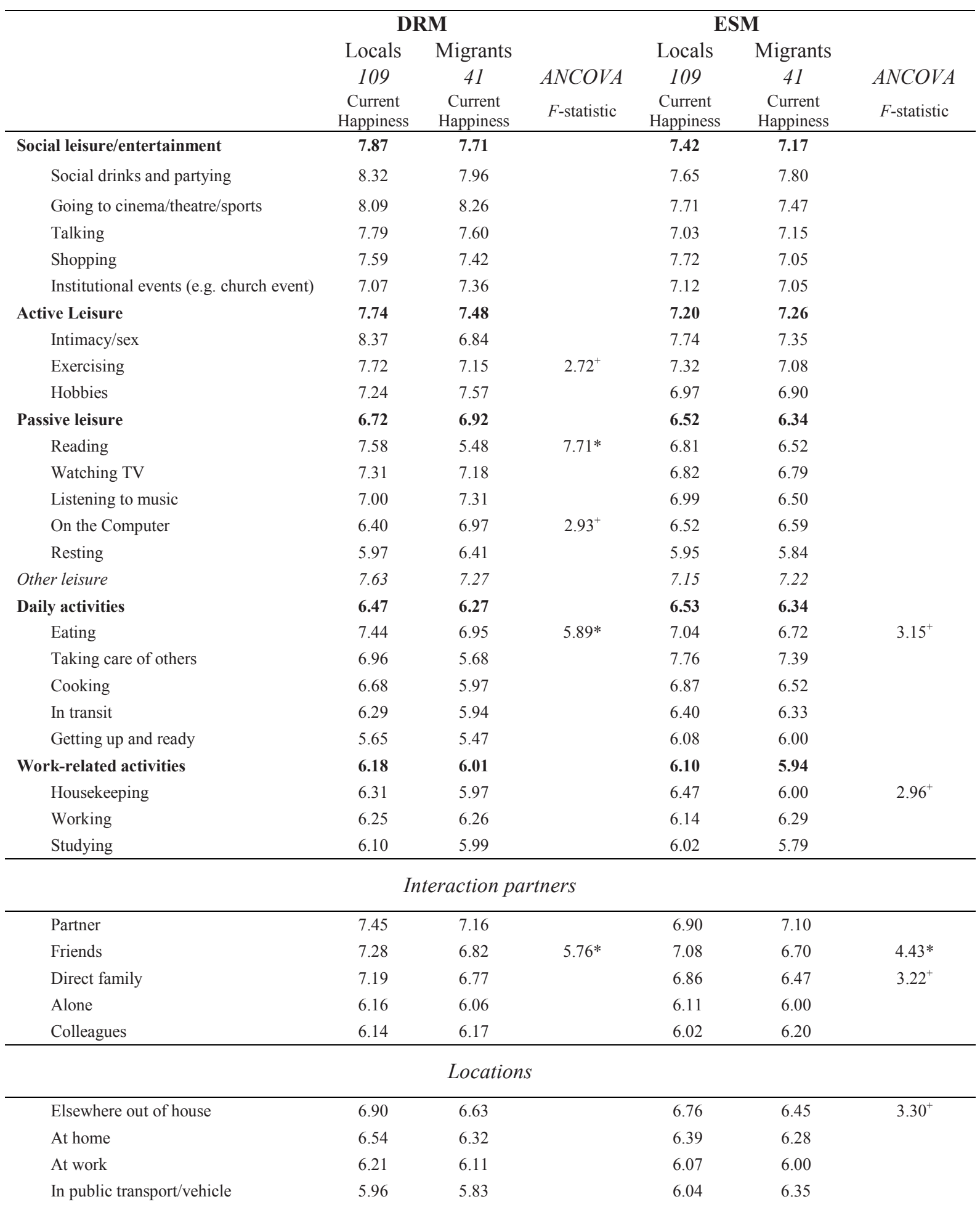

Note: Results are mean-adjusted for differences in all covariates listed in table 1.

The five overarching categories are weighted for frequency of performing the underlying specific activities. Significance levels at the $10 \%, 5 \%$, and $1 \%$ level are denoted by ${ }^{+}, *$, and $* *$ respectively 
Table 6.Unraveling the happiness-difference of eating (DRM).

\begin{tabular}{c|cc|ccc} 
Interaction partners & \multicolumn{2}{c}{ Frequencies } & \multicolumn{3}{c}{ Momentary happiness } \\
& Locals & Migrants & Locals & Migrants & F-statistic \\
\hline Friends & $12 \%$ & $11 \%$ & 7.73 & 7.23 & $2.86+$ \\
Partner & $22 \%$ & $16 \%$ & 7.62 & 7.19 & \\
Direct family & $33 \%$ & $41 \%$ & 7.43 & 7.17 & \\
Colleagues & $1 \%$ & $2 \%$ & - & - & \\
Alone & $32 \%$ & $30 \%$ & 6.73 & 6.64 &
\end{tabular}

Note: Percentages and means are adjusted for differences in all covariates listed in table 1. Significance levels at the $10 \%, 5 \%$, and $1 \%$ level are denoted by,$+ *$, and ** respectively 
Martijn Hendriks, Kai Ludwigs, Ruut Veenhoven 26

Table 7. The incremental value of including daily life experiences.

\begin{tabular}{|c|c|c|c|c|c|c|c|}
\hline \multicolumn{2}{|c|}{$\begin{array}{c}\text { Overall happiness } \\
(0-10)\end{array}$} & \multicolumn{2}{|c|}{$\begin{array}{c}\text { 1-item life satisfaction } \\
(0-10)\end{array}$} & $\begin{array}{c}\text { Affect Balance } \\
(-5 ; 5)\end{array}$ & $\begin{array}{l}S W L S \\
(1-7)\end{array}$ & $\begin{array}{l}\text { Eudaimonia } \\
(1-7)\end{array}$ & $\begin{array}{l}\text { Domains } \\
(0-10)\end{array}$ \\
\hline & $B$ & & $B$ & $B$ & $B$ & $B$ & $B$ \\
\hline \multicolumn{8}{|c|}{ Model 1 - Controlling for personal characteristics $(\mathrm{df}=130)$} \\
\hline \multirow[t]{3}{*}{$-0.64 *$} & $(0.31)$ & $-0.58^{+}$ & $(0.39)$ & $-0.91 * * \quad(0.34)$ & $-0.40 * \quad(0.19)$ & $(0.16)$ & $-0.46^{+}$ \\
\hline & 0.201 & & 0.218 & 0.248 & 0.268 & 0.101 & 0.205 \\
\hline & 0.084 & & 0.104 & 0.138 & 0.161 & -0.030 & 0.089 \\
\hline
\end{tabular}

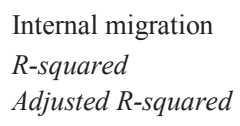

Model 2 - Additionally controlling for time-allocation $(\mathrm{df}=124)$

\begin{tabular}{cccc}
-0.38 & $(0.40)$ & $-0.80^{*}$ & $(0.35)$ \\
0.14 & $(0.17)$ & 0.11 & $(0.15)$ \\
$0.53 * *$ & $(0.19)$ & 0.23 & $(0.17)$ \\
-0.08 & $(0.09)$ & -0.19 & $(0.08)$ \\
-0.01 & $(0.17)$ & -0.24 & $(0.15)$ \\
0.11 & $(0.07)$ & -0.03 & $(0.07)$ \\
$-0.11^{+}$ & $(0.06)$ & -0.05 & $(0.05)$ \\
0.295 & 0.289 \\
0.153 & \multicolumn{3}{c}{0.146}
\end{tabular}

$\begin{array}{cc}-0.26 & (0.19) \\ 0.07 & (0.08) \\ 0.25^{* *} & (0.09) \\ -0.08^{+} & (0.05) \\ 0.07 & (0.08) \\ 0.01 & (0.04) \\ -0.04 & (0.03) \\ 0.336 \\ 0.203\end{array}$

$\begin{array}{cc}-0.24 * & (0.17) \\ 0.12^{+} & (0.07) \\ 0.08 & (0.08) \\ -0.11 * * & (0.04) \\ -0.02 & (0.07) \\ 0.02 & (0.03) \\ -0.02 & (0.03) \\ 0.183 & \\ 0.019 & \end{array}$

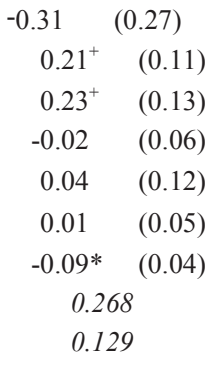

Model 3 - Additionally controlling for 'saddening' effects (df=122)

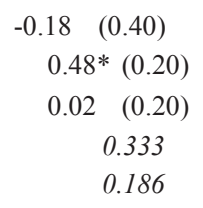

150

$\begin{array}{cc}-0.59 & (0.36) \\ 0.29^{+} & (0.17) \\ 0.25 & (0.18) \\ 0.327 & \\ 0.178 & \end{array}$

150
$-0.19 \quad(0.20)$
$0.21 * \quad(0.10)$
$0.00 \quad(0.10)$
0.363
0.222

150
$-0.13 \quad(0.17)$
$0.21 * * \quad(0.08)$
$0.07 \quad(0.08)$
0.246
0.079

150
$-0.11 \quad(0.27)$
$0.22+$

$0.22^{+} \quad(0.13)$

$0.31 * \quad(0.14)$

0.332

0.185
Note: OLS estimation. Standard errors in parentheses.

Significance levels at the $10 \%, 5 \%$, and $1 \%$ level are denoted by ${ }^{+}, *$, and $* *$ respectively 
Table 8: Two stage treatment model

\begin{tabular}{lccccc}
\hline \multicolumn{1}{c}{ First-stage } & \multicolumn{3}{c}{ Second-stage } \\
\hline \multicolumn{1}{c}{ Probability to migrate } & $\mathrm{B}(\mathrm{SE})$ & Overall happiness & $\mathrm{B}(\mathrm{SE})$ \\
\hline $\begin{array}{l}\text { Distance to psychology- } \\
\text { program (instrument) }\end{array}$ & $0.023 * *(0.00)$ & Internal migration & -0.51 & $(0.56)$ \\
Age & $0.11^{+}$ & $(0.06)$ & & & \\
Gender & 0.02 & $(0.47)$ & $\lambda$ & -0.10 & $(0.41)$ \\
Constant & -4.55 & $(1.36)$ & $\mathrm{N}$ & 101 & \\
& & & $\rho$ & -0.07 & \\
& & & $\sigma$ & 1.44 \\
\hline
\end{tabular}

Note: B's of full set of covariates not reported.

Significance levels at the $10 \%, 5 \%$, and $1 \%$ level are denoted by ${ }^{+}, *$, and ** respectively 